\title{
Espacialidades
}

\section{HERMAFRODITAS NOS SÉCULOS XVI E XVII:}

intersexualidade impossível

Hermaphrodites in the sixteenth and seventeenth centuries: The impossible intersexuality

Ronaldo Vainfas ${ }^{1}$

Artigo recebido em: 17/07/2020.

Artigo aceito em: 25/08/2020.

\section{RESUMO:}

$\mathrm{O}$ artigo discute a relação entre o conceito tradicional de hermafroditismo e o atual conceito de intersexualidade, o primeiro excluindo ou punindo, o segundo afirmativo, tanto do ponto de vista médico quanto no campo das identidades coletivas e individuais. A análise empírica baseia-se em processos judiciais ibéricos dos séculos XVI e XVII, incluindo, finalmente, a transcrição de um manuscrito inédito do processo contra Claudiana da Natividade, freira portuguesa. Conclui a impossibilidade teórica para a formulação do conceito de intersexualidade no contexto intelectual, moral e científico da Era Moderna ou do Antigo Regime.

PALAVRAS-CHAVE: Hermafroditismo; Intersexualidade; Conventos femininos.

\section{ABSTRACT:}

The article discusses the relationship between the traditional concept of hermaphroditism and the current concept of intersexuality, the first excluding or punishing individuals, the second affirmative, both from a medical point of view and in the field of collective and individual identities. The emoirical the analysis is based upon Iberian judicial cases of the 16th and 17th centuries, including, at last, a transcription of an inedict manuscript of the process against Claudiana da Natividade, a Portuguese nun. It concludes on the theoretical impossibility for the formulation of the concept of intersexuality in the intellectual, moral and scientific context of the Modern Age or the Ancient Regime.

KEYWORDS: Hermaphroditism; Intersexuality; Female Monasteries.

1 Doutor pela USP (1988) Professor Titular de História Moderna da UFF, onde ingressou em 1988 e se aposentou em 2015. Pesquisador IA do CNPq. Cientista do Estado do Rio de Janeiro pela FAPERJ. Endereço de e-mail: <rvainfas@terra.com.br>. 


\section{Introdução}

A intersexualidade é um dos temas mais polêmicos da atualidade. Está presente no debate entre a defesa das diversidades sexuais contra os adeptos da homofobia e preconceitos assemelhados. Frequenta controvérsias e decisões jurídicas. É citada em discursos religiosos intolerantes. Continua, enfim, matéria do saber médico nos documentos da OMS.

A principal polêmica se localiza, atualmente, entre os defensores do intersexualidade, membros ou apoiadores do LGBTI $^{2}$, e os adeptos da Organização Mundial de Saúde (OMS), que define as ambiguidades sexuais naturais de alguns seres humanos, como "desvios de desenvolvimento sexual", incluído no rol de doenças. A intersexualidade defendida por uns é considerada patologia pela OMS, ancorada em razões biológicas (BAJO, 2009, p.145)

Os defensores da igualdade de direitos universais para as mais diversas orientações sexuais hoje abriga várias minorias: lésbicas, gays, bissexuais, transexuais e intersexuais. A intersexualidade é uma condição especial dentre tais minorias, pois tem a ver mais diretamente com a morfologia natural dos órgãos sexuais do indivíduo.

O intersexual difere do transexual porque este último se autoconstrói por recusar a identidade de gênero derivada de sua identidade física de nascimento. Transexual é o indivíduo que, por seu comportamento, intervenção cirúrgica ou uso de hormônios, busca adaptar seu corpo ou, pelo menos, sua aparência externa, ao gênero com o qual se identifica. Intersexual é aquele cujos órgãos sexuais ou aparelhos reprodutores não são masculinos ou femininos ou o são de forma incompleta, quando não coexistem em um mesmo corpo individual.

Ainda assim, a definição é controvertida. A Sociedade Intersexual Norte-americana considera que a intersexualidade não deriva fundamentalmente da natureza biológica do indivíduo, mas implica a decisão particular de não se definir seja como homem, seja

${ }^{2}$ LGBTI é uma sigla que significa Lésbicas, Gays, Bissexuais, Transexuais e Intersexuais.

Revista Espacialidades [online]. 2021.1, v. 17, n. 1, ISSN 1984-817X 
como mulher, seja como ambos simultaneamente. Trata-se de uma condição singular, que abriga muitas especificidades e combinações, embora esta mesma perspectiva admita que o fator biológico tem peso decisivo para a construção de uma identidade intersexual, sobretudo para o próprio (INTERSEX SOCIETY, 2008).

A condição intersexual e o conceito que atualmente se lhe atribui, malgrado as polêmicas, são temáticas muito recentes. Podem, no entanto, ser submetidas a um escrutínio histórico, a uma pesquisa baseada em frentes manuscritas e iconográficas na mais longa duração. Em termos vocabulares, o atual intersexual era definido como hermafrodita e logo veremos que tal conceito era pejorativo, excludente e podia sujeitar o indivíduo a confinamentos e castigos.

Quem sabe a história do hermafroditismo - termo hoje exilado das Ciências Humanas e Médicas - possa oferecer alguma contribuição para o tema em foco, a partir de um ponto de vista humanista? Disse humanista no sentido renascentista, isto é, com espírito aberto e tolerante em face das alteridades; não disse bumanitário, que pode exprimir uma ação solidária em relação a outrem - a meu ver positiva - mas contém um certo quê de complacência ou compaixão impertinentes a uma reflexão intelectual.

\section{Uma freira hermafrodita do século XVII}

Claudiana da Natividade era uma jovem freira de um convento agostiniano de Vila Viçosa. Cidade pequena do Alentejo, quase na fronteira com a Espanha, sede do ducado de Bragança. Berço da dinastia do mesmo nome que assumiu a Coroa portuguesa, em 1640, rompendo a chamada União Ibérica.

Pouco se sabe da vida de Soror Claudiana, exceto que ela foi expulsa do convento, em 1622, perdendo o hábito da Ordem dos Eremitas de Santo Agostinho. A condenação resultou de um segredo que, rompendo os muros do convento, tornouse rumor e escândalo público. Claudiana não era do sexo feminino, "por não ter de modo algum natureza de mulher", senão de homem - assim escreveu rei Gregório de 


\section{Espacialididades}

Laude, provincial da citada ordem religiosa em Portugal, na sentença expulsória da freira.

Foi o mesmo provincial que dirigiu as investigações quando os rumores se tornaram públicos, para descrédito do convento, de que havia um homem entre as freiras, fingindo-se de mulher para ingressar no claustro. O juiz inquiriu várias freiras do convento, no estilo inquisitorial, e apurou que Claudiana vivia enroscada com colegas de claustro, procurando-as ou sendo por elas procurada para fazer sexo, usando sua natura masculina como instrumento, que ora estava "recolhida, e outras (vezes) lhe saía para fora, quando se lhe alterava". Quando alterada, sua natura máscula crescia e Claudiana alcançava orgasmos, isto é, sentia "deleitosas seminis efusivas", conforme o protocolo vocabular da época. Em outras palavras, sem metáforas ou vocábulos latinos, Claudiana gozava como homem, pois de homem se tratava, segundo escreveu o provincial, que logo ordenou que fosse ela examinada por parteiras, comprovando-se, por este meio, a natureza viril da jovem freira.

O processo completo de Claudiana da Natividade infelizmente se perdeu, quem sabe o autor este artigo não conseguiu encontrá-lo. Mas ele está resumido na sentença lavrada em 16 de dezembro de 1622, inclusa em um códice da Secção de Reservados da Biblioteca Nacional de Lisboa. Trata-se de um documento fascinante, espantoso para um leitor atual, rico em detalhes sobre "as ações de homem" de Claudiana, além de inúmeros outros indicativos da mentalidade oficial da Igreja e da sociedade seiscentista.

O documento é breve, de modo que vou transcrevê-lo na íntegra, em anexo a este artigo, para atender à curiosidade dos leitores e leitoras e incentivar pesquisas neste campo, quem sabe alguma baseada no processo completo, ora perdido em algum arquivo português - lisboeta ou alentejano. É possível, embora difícil, encontrar o processo nos arquivos da Ordem dos Eremitas de Santo Agostinho ou, sobretudo, no Museu-Biblioteca da Casa de Bragança, em Vila Viçosa. A historiadora Georgina 
dos Santos encontrou documentos fundamentais para seu livro Ofício e Sangue no acervo daquela casa (SANTOS, 2004).

Em todo caso, há uma notícia essencial, registrada ao final da sentença, inclusa no códice da Biblioteca Nacional de Lisboa. Neste trecho, lê-se que a sentença expulsória "foi revogada, no grau de apelação, pelos Juízes Delegados do Papa e depois de quinze anos passados, foi outra vez recolhida esta Religiosa na clausura". A revogação da sentença ocorreu, portanto, em 1637, e o citado registro datado de 23 de dezembro de 1639.

Este pequeno trecho não diz quase nada, mas talvez diga tudo - decerto estimula conjecturas irrefreáveis, inerentes ao ofício de historiador (a), como afirmou Carlo Ginzburg acerca do trabalho historiográfico (GINZBURG, 1990, p.183).

Informa, em primeiro lugar, que houve apelação da sentença de 1622 que alcançou Roma, a ponto de o papa enviar núncios para reexaminar o caso. Isto sugere que Claudiana provinha de família abastada o suficiente para custear processo moroso, certamente caro, a começar pelo envio de procuradores à cúria pontifical. Se era proveniente de família grada, o caso de Claudiana confirma o que já se escreveu em várias obras sobre a procedência social da maioria das freiras nos conventos da Época Moderna, em particular os ibéricos. Eram moças de família ricas, proprietárias de terras, que preferiam enviar algumas filhas a um convento, pagando dote inferior do que pagariam ao esposo se as casassem. Questão de cálculo: era menos custoso meter algumas filhas no claustro do que dotar infinidade de noivos, com perdas fundiárias indesejáveis (SOEIRO: 1974, 219-220). Por vezes eram comerciantes endinheirados que enviavam filhas ao claustro de alguma ordem religiosa, em especial se cristãos-novos, empenhados em demonstrar sua piedade católica e com isso afastar quaisquer suspeitas de heresia judaica (SANTOS, 2006, p.340).

Em segundo lugar, o trecho citado permite imaginar o sofrimento de Claudiana, quinze anos afastada do convento, onde se sentia feliz até cair em desgraça. Deprimida com o retorno ao claustro familiar, além de vexada pelo escândalo, talvez 
confusa sobre a sua própria identidade sexual. Uma depressão similar à de Herculine Barbin, no século XIX, cuja trajetória foi examinada por Michel Foucault com base no diário da personagem (FOUCAULT, 1983). Herculine se matou, dilacerada pelo dilema de sua intersexualidade, conceito que estava longe de existir no século XIX, quanto mais no XVII. Neste século, o indivíduo nascia homem ou mulher.

Se mostrasse sinais de possuir ambos os sexos, era considerado hermafrodita, palavra de origem grega alusiva ao filho do deus Hermes e da deusa Afrodite, cujo corpo era bissexual. Possuía ovário e testículos. Conceito similar, mas não idêntico, ao de andrógino. Também de origem grega, a palavra misturava homem (andro) com mulher (gyne), mas não era exclusivo de ambiguidades fisiológicas, incluindo comportamentos socioculturais referidos aos papéis e ao habitus de cada gênero. A imagem abaixo pertence ao imaginário medieval, representando um indivíduo morfologicamente duplo, com um seio e barba. Vale dizer que figuras deste tipo pertenciam ao campo da teratologia que, no remoto passado, significava o estudo de monstros (terato, em grego), mas transformado pela ciência médica em estudo das causas e padrões de desenvolvimento anormal do corpo humano. Como o hipersutismo, isto é, pilosidade excessiva em partes do corpo feminino em geral pouco peludas ou sem pelos (BAJO: 2009, p.145). Em todo caso, como já disse, o hermafroditismo por vezes se confundia com o de androginia, na cultura erudita ocidental, sendo visto entre a monstruosidade física e a patologia genética. Um erro da natureza. (DARMON, 1981, p.101) 


\section{Espacialidades}

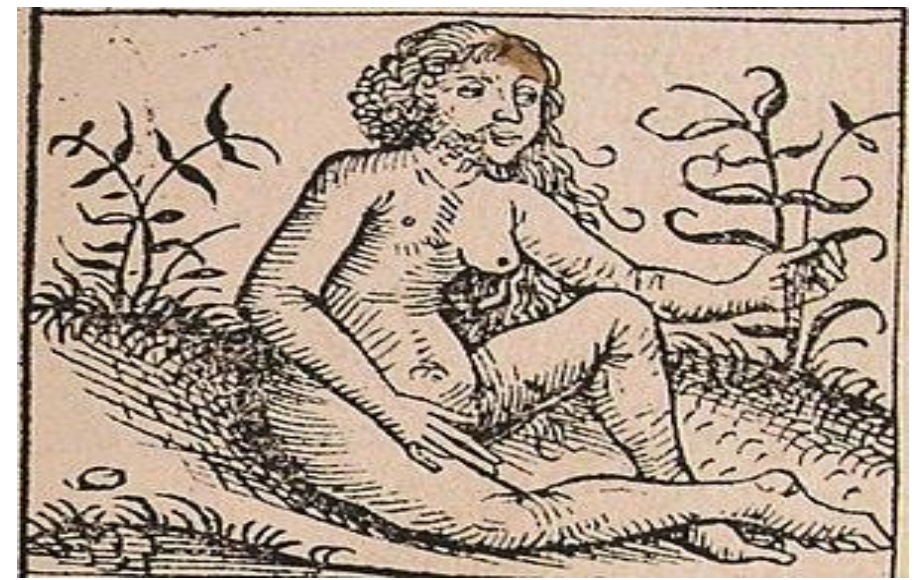

Gravura medieval de um ser humano andrógino, com barba e apenas um seio. Crônica de Nüremberg, de Hartmann Schedel, incunábulo publicado no século XV.

Em terceiro lugar, voltando ao texto de frei Gregório à luz do comentário anterior, é perfeitamente possível, senão certo, que Claudiana da Natividade fosse hermafrodita, como se dizia à época. O conceito era pouco usado, como no caso de Claudiana, mas consta de vários outros documentos coetâneos.

No julgamento de Claudiana de Jesus não se cogitou do hermafroditismo., por ignorância ou teimosia do juiz encarregado. A sentença de frei Gregório a definiu como homem - inadmissível, por isso, em um claustro feminino. Quinze anos depois, considerando a sua readmissão no convento, ela foi reconhecida como mulher. Um caso típico de ambiguidade fisiológica da personagem, pois é pouco credível que um indivíduo considerado homem em 1622, com base no exame de parteiras, tenha se transformado em mulher, em 1639, no juízo dos núncios apostólicos.

Um forte indício do hermafroditismo de Claudiana, que Frei Gregório omitiu na sentença, reside no argumento que usou para explicar a entrada de Claudiana no convento. Afirma que a moça "se meteu Religiosa por saber de si que não tinha vaso natural como as mais mulheres para poder casar". Ora, se Claudiana fosse homem dotado de pênis, como diz frei Gregório, poderia perfeitamente casar, enquanto tal, com alguma mulher. Por qual razão um homem, logo desprovido de vagina, cogitaria ingressar em um convento? O argumento de frei Gregório carece de fundamento. A 
expectativa de contrair matrimônio com alguém do sexo masculino, atribuída a Claudiana só faria algum sentido se nela houvesse algum traço feminino, físico e/ou emocional. Claudiana sentia-se mulher e/ou assim foi considerada pelos pais.

O mais provável é que, ao contrário do que registrou frei Gregório, na altura em que a família de Claudiana "a meteu no convento", ela era menina, provavelmente dotada do "vaso natural" que o juiz se recusou a ver e admitir. Ao longo da vida conventual, Claudiana desenvolveu também o órgão masculino, despertando para novos desejos sexuais, então como homem.

Os historiadores que examinaram casos de hermafroditas no século XVII, constataram que tais indivíduos vivenciaram antes a puberdade feminina e depois a masculina, em graus variados, do que resultou mudanças de orientação sexual em suas histórias de vida. Isto está perfeitamente de acordo com a Biologia, pois a menarca precede, em dois ou três anos, a puberdade masculina (CASTILHO \& BARRAS FILHO, 2000).

O caso de Claudiana deve ter seguido o mesmo padrão, que frei Gregório não admitiu, deturpando os fatos, obsedado em afirmar que Claudiana era homem. Para reforçar seu argumento, frei Gregório chegou a escrever que Claudiana sentia “aborrecimento" em face de "exercícios mulheris" na vida conventual, em contraste com “o afeto que procurava e exercitava as ações de homem”. Eis um trecho truncado do documento, pois fica-se sem saber ao certo a que "exercícios mulheris" e a quais “ações de homem” aqui se referiu o provincial dos eremitas. Se acaso se referia aos trabalhos realizados no convento, seria possível distinguir tarefas de mulheres e de homens em uma instituição de clausura feminina? Se, por outro lado, frei Gregório se referia a exercícios sexuais, estaria a admitir, sem qualquer cerimônia, que o convento de Vila Viçosa era um refúgio de mulheres luxuriosas?

A primeira hipótese é plausível, embora improvável, pois as reclusas eram proibidas de trabalharem em serviços externos ao lado de homens para tanto contratados. Talvez frei Gregório se referisse a trabalhos pesados, ao mencionar 
“ações de homem”, neste contexto, reservando a expressão "exercícios mulheris” aos trabalhos que a cultura misógina da época considerava femininos. Folhetos volantes portugueses que circulavam no Portugal quinhentista divulgavam a imagem da mulher ideal como esposa fiel, mãe zelosa e responsável pela administração doméstica modelo extensivo, salvo a maternidade, às reclusas conventuais, tidas como "esposas de Deus", fidelíssimas, quando professavam os votos da respectiva ordem religiosa (SILVA, 1983, p. 38-54).

A segunda hipótese é improvável, mas cabível, pois era comum a prática de relações sexuais nos conventos, seja entre as freiras, seja entre elas e homens, como os padres confessores, ou mesmo laicos que se infiltravam nos claustros, abrindo alçapões, ou se pendurando nas grades das janelas. Vários conventos possuíam (e possuem) ferros pontiagudos, em perpendicular às grades, para evitar contatos íntimos entre as moças de dentro e pessoas de fora. Aliás, o uso do adjetivo gradeira, no sentido pejorativo, por vezes atribuído às religiosas da época, não raro aludiam a "conversações desonestas"3 que umas e outras praticavam nas janelas do prédio conventual ${ }^{4}$. Inúmeras fontes da época mencionam tais amores, como o texto de frei João de Mansília, datado do século XVIII, A história escandalosa dos conventos da Ordem de São Domingos (MANSÍLIA, 1983).

O fato é que este trecho da sentença não oferece pista alguma senão para confirmar o empenho do juiz em masculinizar Claudiana a todo custo.

\footnotetext{
${ }^{3}$ Expressão alusiva a contatos sexuais.

${ }^{4}$ A palavra gradeira, porém, era usada oficialmente para designar as freiras que acompanhavam colegas de claustro para falar com alguém no locutório, isto é, para vigiá-las. Na prática, todo este cuidado era por vezes inútil.
} 


\section{Drama dos hermafroditas}

O drama de Claudiana da Natividade foi vivenciado por outros indivíduos na Europa da época, por vezes de forma mais dura.

Michèle Escamilla estudou o caso fascinante de um certo Eleno ou Elena Céspedes - o gênero depende do momento em que o indivíduo teve o seu corpo examinado - na segunda metade do século XVI. Nascido em 1545 na região de Granada, na andaluzia, era filho de um camponês e de uma escrava negra, possivelmente mourisca. A historiadora afirma que ele ou ela nasceu "na junção crucial do mundo livre e da escravidão, do mundo rural e da sociedade urbana" (ESCAMILLA, 1985, p.168). Comentário, a meu ver, literário e retórico, ainda que sociologicamente pertinente, ao sugerir algum parentesco entre o hermafroditismo do personagem e suas ambiguidades sociais.

Mas o artigo é brilhante e fartamente documentado. A personagem foi batizada como Elena, tida como menina, portanto, e muito cedo foi alforriada pela senhora de sua mãe, que se afeiçoou à menina e lhe deu o nome de família. Quando Elena chegou aos 15 anos, a senhora fê-la casar-se com um pedreiro de quem havia engravidado, mudando-se com marido e filho para um vilarejo nas cercanias de Cádiz, sul da Espanha. Pois eis que quando Elena tinha cerca de 20 anos, o marido descobriu que sua esposa tinha uma dupla morfologia sexual. Custou a perceber ou preferiu não percebê-la e Elena acabou detida pelo corregedor do crime, acusada de ser homem que se fazia de mulher. O fato repercutiu na vila, a ponto de Elena escapar, na primeira chance, abandonando o marido e o filho.

O personagem reaparece na documentação quando tinha cerca de 40 anos. Adotou o nome de Eleno Céspedes, masculinizando-se, e passou a viver nas cercanias de Madri, depois de servir como soldado no exército castelhano de Filipe II. Ali trabalhou como cirurgião-barbeiro - um misto de dentista, barbeiro e enfermeiro até que, em 1586, casou-se com Maria del Caño, na igreja de San Benito. Matrimônio católico, com o aval do pai da noiva, Francisco del Caño. 
Não tardou para que, no vilarejo em que vivia o casal, surgisse o rumor de que Maria continuava virgem, embora casada, notícia espalhada pela própria. Se assim era, o casamento poderia ser anulado, segundo o direito canônico, pois a cópula conjugal era definida como “a união corporal entre Cristo e a Igreja”, elemento indispensável à consumação do matrimônio católico. A queixa de Maria não foi excepcional. Pierre Darmon, em livro clássico sobre a França da época, examinou vários casos em que mulheres casadas com homens impotentes, recorreram à justiça eclesiástica para anular o matrimônio, descobrindo alguns hermafroditas entre eles (DARMON, 1979, 211-221).

No caso de Eleno, foi própria Maria a primeira a ser convocada pelas autoridades seculares para esclarecer o assunto, em 1587. Examinada por parteiras, foi declarada como "mulher virgem". Considerada cúmplice da fraude, Maria foi presa, bem como Eleno, e o caso foi parar na Inquisição. O réu era um sodomita por deitar-se com mulher sendo mulher? Seria bígamo, pois os inquisidores souberam que ele se havia casado antes com homem, fingindo-se de mulher? A tragédia que se abateu sobre Eleno agigantou-se.

Mas seu drama vinha de longe. A documentação contém informações cruciais. De como Elena descobriu-se Eleno, ainda no tempo em que era esposa e mãe. De como se atormentou quando viu crescer um pênis, ou quase isto, por cima de sua vagina. De como sofreu quando o marido descobriu sua ambiguidade morfológica. De como resolveu assumir a sua masculinidade, fugindo do marido, abandonando o filho e, mais, de como tentou, por várias vezes, se automutilar, costurando a entrada de sua vagina. Médicos da Inquisição registram as cicatrizes dessas operações que ele perpetrou em si mesmo. Eleno se comportou com máximo brilho, diante os inquisidores que, razoavelmente, lhe aplicaram pena leve, como veremos adiante.

Há diversos casos de hermafroditismo que foram levados à Justiça eclesiástica, secular ou inquisitorial nos séculos XVII e XVIII. Jonas Roelens, em 
artigo recente, estudou vários casos na Flandres, em especial em Bruges, de mulheres acusadas de sodomia foeminarum, onde uma das parceiras era de fato hermafrodita, segundo exames médicos. (ROULENS, 2016-p.11-34)

Mas os juízes da época, seculares ou religiosos, não tinham a menor condição de identificar o que hoje é chamado de intersexualidade, e por vezes custavam a admitir o hermafroditismo, como no caso de Claudiana. Empenhavamse, antes, em determinar se o réu era homem ou mulher, criminalizando-o por manter relações sexuais com pessoas do mesmo gênero.

A situação dos hermafroditas era terrível, suspeitos sempre de cometer sodomia, sobretudo se mulheres. O maior especialista no assunto na época era LuigiMaria Sinistrari, teólogo italiano que, no fim dos seiscentos, escreveu um fabuloso tratado sobre o assunto, num tempo em que os juízes discutiam se as mulheres, naturalmente desprovidas do falo, poderiam cometer o pecado da sodomia. No juízo de Sinistrari, a mulher só poderia penetrar, deflorar ou corromper outra fêmea se possuísse dentro da vulva um grande nymphium, uma "excrescência carnal” mais avantajada que o comum dos clitóris, devidamente apto a derramar sêmen no ânus da parceira.

Sinistrari foi além, afirmando que as mulheres etíopes (africanas) tinham mais propensão a possuir o clitóris avantajado, confundindo, talvez de propósito, o hermafroditismo com a prática da sodomia (Apud: BELLINI, 1987, p.87). Sinistrari era teólogo metido a médico ou vice-versa. Mas é também certo que, na época, como atualmente, relações homoeróticas entre mulheres ou homens, recorriam a falos artificiais para aumentar o prazer. Na Bahia do século XVI, Isabel Antônia era conhecida publicamente como "a do veludo", pois usava um pênis aveludado para suas relações sexuais com a companheira, Francisca Luís5. No século XVIII, a alemã Catharina Linck, dizendo-se homem, foi decapitada por usar um pênis de couro com sua esposa (ERICKSSON, 1980-1981, p. 37)). Montaigne nos conta, em seu Diário

\footnotetext{
${ }^{5}$ Instituto Arquivo Nacional da Torre do Tombo. Inquisição de Lisboa, processo 13.787
} 
da viagem à Itália, sobre sete ou oito mulheres que tinham optado por vestir-se e viver como homens, uma das quais chegaria a casar-se, terminando seus dias enforcada, em 1580 (CROMPTON, 1980-1981, p.17).

Alguns casos, dentre tantos, não envolviam, porém, quaisquer "instrumentos penetrantes". $\mathrm{Na}$ sua maioria, eram amores ou encontros sexuais femininos, envolvendo sexo oral, penetrações com dedos e sugação de mamilos (BROWN, 1987, p.172). Em pouquíssimos casos, estava envolvido um hermafrodita nesses processos.

\section{O hermafroditismo na Justiça}

Os juízes atuantes em julgamentos de indivíduos intersexuais não sabiam bem o que fazer diante de uma realidade que desconheciam, pois eram teólogos ou formados em Leis (Direito). Sequer os médicos - chamados de físicos, na época conheciam a fisiologia de indivíduos biologicamente intersexuais.

Quando juízes mais criteriosos submetiam hermafroditas a exames médicos, a sentença era atenuada, como se eles intuíssem ou soubessem que o hermafroditismo era congênito e natural. $O$ caso de Eleno Céspedes é exemplar, tanto do conhecimento do réu sobre sua natureza híbrida, como da tolerância dos inquisidores. Acusado de sodomia (crime contra a natureza humana), por tentar copular com a esposa, sendo mulher, afirmou: "no son contra naturaliza los hermafroditos". Acusado, então, de bigamia, por ter se casado no rito católico por duas vezes, sendo o primeiro cônjuge vivo, defendeu-se: "cuando me casé con hombre, prevalescía en el sexo femenyno (...), pero después prevalescía en el sexo masculino y me pude casar con mujer" (Apud: ESCAMILLA, 1985, p.178).

Os inquisidores se deixaram convencer pela lógica irreprochável do réu e o condenaram a servir como jardineiro em um convento ou mosteiro. Destruíram sua vida? Talvez, mas não o mandaram matar nem degredar para as galés del rei. 
Claudiana da Natividade, nossa freira hermafrodita do Alentejo, teve melhor sorte, pois foi reintegrada ao Convento dos Eremitas de Santo Agostinho. Mas só o foi após 15 anos de apelações e contraditas judiciárias, sofreu um bocado e morreu sem saber se era homem ou mulher.

\section{Ciência, Cultura e História}

A definição corrente de intersexualidade, como disse no início do artigo, diz respeito a uma pessoa que, naturalmente, sem qualquer intervenção médica, desenvolve características sexuais do sexo feminino e do masculino. A intersexualidade não é unívoca, segundo os especialistas. Algumas pessoas intersexuais nascem com órgãos genitais considerados atípicos; outras nascem com genitais típicas de um ou outro gênero; umas possuem cromossomas XX e são atribuídas ao sexo masculino; outras possuem cromossomas XY e são atribuídas ao sexo feminino, entre outras maneiras de ser intersexual. (INTERSEX SOCIETY, 2008).

Eis a definição científica atual, um tanto anódina, a meu ver, pois sugere eventos genéticos na formação do indivíduo, ao mesmo tempo em que admite "outras maneiras de ser intersexual". Quais outras? Isto me lembra os dilemas dos médicos do século XVII, que sequer tinham a noção do conceito de cromossoma, para não falar dos juízes - seculares ou eclesiásticos.

No tempo de Claudiana da Natividade, os juízes, em sua maioria, preferiam ignorar o hibridismo sexual dos indivíduos. Rejeitavam mesmo as lições da teratologia, que os consideravam como aberrações monstruosas. A medicina não oferecia respostas sore as causas hermafroditismo. A cultura politicamente correta de hoje designa o antigo hermafroditismo como intersexualidade, sublinhando a escolha individual, embora admita uma morfologia natural mais ou menos incerta. Como disse 
Eleno Céspedes aos inquisidores no fim do século XVI: “os hermafroditas não são contra a natureza".

Admirável a posição de Eleno, quase um esboço do moderno conceito de intersexual. Mas ele não prosperou no seu conceito, pois foi considerado homem e confinado, como vimos, a trabalhar como jardineiro em um convento. Claudiana da Natividade teve melhor sorte porque, embora intersexual, foi reconhecida como mulher e readmitida no convento alentejano. Era o que ela talvez desejasse - quem sabe seus pais: voltar ao convento como freira, apesar de, no foro íntimo, sentir ou ter sentido, desejos masculinos, quinze anos antes. Quem sabe se identificava mais como homem do que mulher, embora não fosse nem um nem outra?

Os intersexuais, ambivalentes ou incertos, eram classificados como homem ou mulher, malgrado a sua ambiguidade genital. Não tinham opção. Não havia lugar para ambiguidades genitais. Tempo de intolerância moral e sexual mesclada com frouxidão judiciária. Os próprios juízes percebiam que tais indivíduos não mereciam os piores castigos do Estado ou da Igreja, pois não sabiam tipificar o crime de uma morfologia biológica incerta. Os inquisidores ao menos reconheciam que não havia "erro de fé" nesses casos.

\section{ANEXO - Traslado da sentença contra Claudiana da Natividade 6 Secção de Reservados da Biblioteca Nacional de Portugal, códice 854, fólio} 207.

Nós, Frei Gregório de Laude, Provincial da Ordem dos Eremitas de Santo Agostinho nestes Reinos de Portugal, por acudirmos aos rumores que havia no Convento de Santa cruz de Vila Viçosa e outros avisos que tivemos de que soror Claudiana da Natividade era homem e que se devia com diligência atalhar os perigos que se podiam temer, mandei fazer um sumário de testemunhas das quais e da confissão da dita soror Claudiana, e exames que lhe foram feitos por Parteiras, se

\footnotetext{
${ }^{6}$ A transcrição teve a ortografia modernizada. O último trecho em itálico foi breve nota acrescida, em 1639, à sentença original de 1622.
} 
prova que a dita Soror Claudiana se meteu Religiosa por saber de si que não tinha vaso natural como as mais mulheres para poder casar, e prova-se mais, que foi algumas vezes apalpada e vista por várias pessoas que lhe acharam natureza de homem e dando-o muitas vezes a entender, ainda que outras se retratava e encobria. Prova-se, e consta por sua confissão, que as as ações assim naturais como deleitosas seminis efusivas as fazia pela natureza de homem, que algumas vezes tinha recolhida e outras se lhe saía parafora, quando se lhe alterava. Prova-se mais, pelo exame que the foi feito, não ter de modo algum natureza de mulher, nem vaso seminis recepcicio, antes em o lugar do dito vaso, apontar natureza de homem, e sobretudo, vista sua confissão, em que diz querer salvar sua alma e confessar, que até agora se encobria com vergonha do pejo natural; e que agora, pois está seu segredo descoberto, ela se declarava que conhecia de si não ser mulher, senão homem, e pedia se lhe desse remédio conveniente à sua alma e a sua honra. O que tudo visto e o mais que de si se alcançou por informação e testemunhos de muitas religiosas do aborrecimento que adita Soror Claudiana tinha aos exercícios mulheris, e o afeto com que procurava e exercitava ações de homem, e com o mais que nos Autos consta: Christi Jesu Nomine Invocato, julgo a dita Soror Claudiana da Natividade por incapaz de viver em clausura com as virgens consagradas a Deus, e como tal lhe seja logo despido o Hábito de nossa sagrada Religião, e dentro de duas horas seja lançada da clausura e a relevo das penas em que incorreu, tendo respeito à sua simplicidade 7 . Dada em Vila viçosa aos 16 dias de Dezembro de 1622. Sob o nosso sinal e selo. Frei Gregório de Laude.

Esta Sentença foi revogada no grau da apelação pelos Juizes Delegados do Papa e depois de quinzenos passados foi outra vez recolbida esta Religiosa na clausura pela sentença que traz Themudo, Part 4, Dec. 23, num. 39.

\section{REFERÊNCIAS}

BAJO, José Manuel. Fundamentos de la reproducción. Buenos Aires: Editora Medica Panamericana. 2009.

BELLINI, Lígia. A coisa obscura: mulher, sodomia e inquisição no Brasil colonial. $2^{\mathrm{a}}$ ed. Salvador: EDUFBA, 2014.

\footnotetext{
${ }^{7}$ Simplicidade, no caso, diz respeito à escassez de conhecimentos da ré, mormente nesta matéria de que era acusada, e não à sua origem social.
} 
CASTILHO, Silvia \& BARRAS FILHO, Antônio. Crescimento pós-menarca. Arquivos Brasileiros de Endocrinologia e Metabologia, vol. 44 (3), 2000.

Disponível em: https://www.scielo.br/scielo.php?script=sci_arttext\&pid=S000427302000000300003

CROMPTON, Louis. The Myth of Lesbian Impunity. Capital Laws from 1270 to 1791. In: LICATA, S. J. et al. (org.). Historical Perspectives on Homosexuality. New York, Haworth Press, 1980/1981, p. 11-25.

DARMON, Pierre. Le Tribunal de L'impuissance. Paris, Seuil, 1979.

DARMON, Pierre. Le Mythe de la procréation à L'Age Baroque. Paris, Seuil, 1981.

ERIKSSON, Brigitte. A Lesbian Execution in Germany, 1721: the Trial Records. In LICATA, S. J. et al.(orgs.). Historical Perspectives on Homosexuality. New York, Harworth Press, 1980/1981, p. 27-39.

ESCAMILLA, Michèle. A propos d'un dossier inquisitorial des environs 1590: les étranges amours d'un hermaphrodite. In REDONDO, A. (org.) Amours légitimes, amours illégitimes en Espagne. Paris, Publications de la Sorbonne, 1985.

FOUCAULT, Michel. Herculine Barbin. Diário de um hermafrodita. Rio de jneiro: Francisco Aves, 1983.

GINZBURG, Carlo. Provas e possibilidades - à margem de Il Rittorno de Martin Guerre. In: A microbistória e outros ensaios. Lisboa, Martins Fontes, 1992, 179-202.

INTERSEX SOCIETY OF NORTH AMERICA. What is intersex? Rohnert Park Califórnia, 2008. Disponível em: https://isna.org/faq/what_is_intersex/

MANSÍLIA, Frei João de. A bistória escandalosa dos conventos da ordem de São Domingos em Portugal (1774-1776). Lisboa, Vega, 1983.

ROULENS, Jonas. A Woman Like Any Other: Female Sodomy, Hermaphroditism and Witchcraft in Seventeenth-Century Bruges. Journal of Women's History. 19 (4), 2016. Disponível em:

https://www.researchgate.net/publication/312332238_A_Woman_Like_Any_Other _Female_Sodomy_Hermaphroditism_and_Witchcraft_in_Seventeenth-

Century_Bruges

SANTOS, Georgina dos. Ofício e sangue - a Irmandade de São Jorge e a Inquisição na Lisboa moderna. Lisboa: Colibri, 2004.

SANTOS, Georgina Silva dos. "Isabel da Trindade: o criptojudaísmo nos conventos portugueses seiscentistas". In: VAINFAS, R. et al. (orgs.). Retratos do Império. 


\section{Espacialidades}

Trajetórias individuais no mundo português nos séculos XVI a XIX. Niterói: EDUFF, 2006, p. 333-356.

SILVA, Maria Regina N. X. A. Tavares da. O tema da mulher em folhetos volantes portugueses. In MARQUES, H. de O. et al. A mulher na sociedade portuguesa. Coimbra, Faculdade de Letras, 1986, p. 39-54.

SOEIRO, Susan A. The Social and Economic Role of the Convent: Women and Nuns in Colonial Bahia, 1677-1800. Hispanic American Historical Review, v. 54 (2): 209232, 1974. 